\title{
Genetic characterization of far eastern species of the genus Crepidostomum (Trematoda: Allocreadiidae) by means of 28S ribosomal DNA sequences
}

\author{
Dmitry M. Atopkin ${ }^{1,2 *}$, Marina B. Shedko ${ }^{1}$ \\ ${ }^{1}$ Lab. Parasitology, Institute of Biology and Soil Science, Far Eastern Branch, Russian Academy of Sciences, Vladivostok, Russia \\ ${ }^{2}$ Far Eastern Federal University, Vladivostok, Russia \\ Email: ${ }^{*}$ atop82@gmail.com
}

Received 14 November 2013; revised 13 January 2014; accepted 26 January 2014

Copyright (C) 2014 Dmitry M. Atopkin, Marina B. Shedko. This is an open access article distributed under the Creative Commons Attribution License, which permits unrestricted use, distribution, and reproduction in any medium, provided the original work is properly cited. In accordance of the Creative Commons Attribution License all Copyrights (C 2014 are reserved for SCIRP and the owner of the intellectual property Dmitry M. Atopkin, Marina B. Shedko. All Copyright @ 2014 are guarded by law and by SCIRP as a guardian.

\section{ABSTRACT}

Genetic divergence and phylogenetic relationships of four species of the genus Crepidostomum Braun, 1900 sensu Caira, Bogěa (2005) were revealed using partial sequences of $28 \mathrm{~S}$ ribosomal RNA gene. Genetic divergence between $C$. $c$ f. farionis (Muller, 1784) and $C$. nemachilus Krotov, 1959 was $3.1 \%$, which corresponds to the mean value of interspecific divergence between Crepidostomum species. These two species, therefore, can be recognized as bonafide species. However, we found no genetic differences between 28S rRNA gene sequences of $C$. nemachilus and $C$. $c f$. metoecus Braun, 1900 in spite of considerable morphological and ecological differences. Maximal values of genetic $p$-distances were revealed between $C$. $c f$. auriculatum Wedl, 1857 and C. cf. farionis. Phylogenetic relationships of Crepidostomum spp. for which sequence data are available, along with species in other related genera (Bunodera Railliet, 1896 and Allocreadium Loss, 1900) showed a paraphyly of the genus Crepidostomum. Considerable differentiation of C. cf. auriculatum from other Crepidostomum species was revealed, which may reflect the original description of this species in a separate genus Acrolichanus Ward, 1917. Our results are consistent with the conventional systematics that places the four genera (Crepidostomum, Bunodera, Megalogonia and Allocreadium) within the same family.

\section{KEYWORDS}

DNA; Sequencing; Crepidostomum; Acrolichanus;

\footnotetext{
*Corresponding author.
}

Trematoda; Digenea; Phylognetic Relationships

\section{INTRODUCTION}

Species of the Allocreadiidae are important components of the parasite fauna of the freshwater fishes and their systematics have not been clarified yet. The membership of these trematodes to either family Allocreadiidae Stossich, 1903 or family Bunoderidae Nicoll, 1914 has been discussed in the literature [1-5]. However, molecular phylogenetic analyses that have included these trematodes have recovered them in a monophyletic Allocreadiidae [6-8]. The genus Crepidostomum sensu Caira, Bogěa, 2005 is one of the most taxonomically confused groups of trematodes of the family Allocreadiidae, which contains 40 nominal and 24 valid species. The life cycle of Crepidostomum spp. involves freshwater bivalves as first intermediate hosts, freshwater arthropods as second intermediate hosts, and freshwater fishes from a variety of families as definitive hosts. The most widely distributed species of this genus are C. auriculatum Wedl, 1857, C. farionis (Muller, 1784) and C. metoecus Braun, 1900. It is not surprising that these three species have been known by numerous synonyms. For example, a trematode of salmons was reported as $C$. ussuriensis by Layman (1930) [9] for south territory of Russian Far East from Salvelinus sp. Later this species was recognized as synonym of $C$. farionis by Skrjabin and Koval (1966). Another established species for Russian Far East-C. nemachilus, described by Krotov (1959) [10] from Barbatula toni, was recognized as synonymous taxon of $C$. ussuriensis [1]. After that the taxonomical status of this species was not discussed in the Russian literature. Shi- 
mazu (1990) touched upon issue of taxonomic status of C. nemachilus and considered this species as synonymous with $C$. farionis [11]. The problem of validity of $C$. nemachilus still needs to be resolved.

The taxonomy of Crepidostomum auriculatum, an intestinal flatworm of sturgeons, has a confusing history, and was reviewed by Choudhury (1997) [12]. It was first described as Distoma auriculatum by Wedl from the sterlet Acipenser ruthenus from Austria (River Danube). This species was first reported in North America by Linton in 1897 under the same name [13]. Pratt was the first who used the name "Crepidostomum auriculatum" for description of this species [12]. The first detailed description of C. cf. auriculatum, based on whole mounts and histological sections, was given by Skwortzoff (1927, 1928) from sterlet Acipenser ruthenus from Volga River [14,15]. Taxonomical study of Hopkins (1933) resulted in the recognition of all North American forms from sturgeons as C. lintoni (Pratt in Linton, 1901) and recognition of $C$. auriculatum from sterlet as separate species [16]. Later, these two species were recognized as synonymous by many researchers [1,3,17-19]. Crepisodostomum auriculatum was also considered by Hopkins (1934) as synonymous with Acrolichanus similis, described by Wisniewski in 1933 from Salmo trutta and Oncorhynchus mykiss [20]. But further taxonomical studies showed that $A$. similis and C. auriculatum are separate species [3,12]. According to Shul'man (1954) and Choudhury (1997), there are trends in a few differences between European and North American C. auriculatum specimens in spite of agreement in all essential details $[12,19]$. Thus, placing C. auriculatum in either Crepi- dostomum or Acrolichanus is still a topical problem, as the identity of specimens of this species from different locations North America, Europe and Northern Asia, including Russian Far East. The aim of our study is to clarify the taxonomy of far eastern Crepidostomum species by genetic characterization using patrial sequences of the $28 \mathrm{~S}$ rRNA gene.

\section{MATERIALS AND METHODS}

Trematodes C. cf. auriculatum, C. cf. farionis, C. cf. metoecus and C. nemachilus were obtained during parasitological field work in 2008-2010 from south of Russian Far East (water bodies of Primorsky Region and Amur River near Nikolaevsk-na-Amure city). Morphology of 1000 specimens (alive and mounted in Canada balsam) of trematodes was examined and four species were revealed. For molecular analysis adults of each species, obtained from the intestine of definitive host species, were preliminary checked under slight pressure between two glass slides and then fixed in 96\% ethanol. Species identification was performed according to different authors $[1-3,10]$. Additionally it was examined nine syntypes of C. nemachilus from muzeum of K. I. Skrjabin All-Russia Institute of Helminthology, Moscow, Russia (№ 7506 and 7507). List of species, incorporated into analysis, presented in Table 1. We used symbol "cf." for the names of three species (C. cf. auriculatum, C. $c f . f a-$ rionis, $C$. cf. metoecus) because of these specimens weren't compared with the trematodes from type location in spite of preliminary identification of these species by morphology.

Table 1. List of the taxa incorporated in sequence analysis.

\begin{tabular}{lcccc}
\hline Species & $\mathrm{n}$ & Host & Author & EMBL reg. number \\
\hline Crepidostomum cf. auriculatum & 15 & Family. Allocreadiidae & & FR821371 - FR821385 \\
Crepidostomum cf. auriculatum & 3 & Acipenser schrenkii & This study & FR821386 - FR821388 \\
Crepidostomum cf. auriculatum & 11 & Huso dauricus & This study & FR821389 - FR821398 \\
Crepidostomum cf. farionis & 6 & Oncorhynchus masou & This study & FR821399 - FR821404 \\
Crepidostomum cf. metoecus & 3 & Salvelinus leucomaensis & This study & FR821405 - FR821407 \\
Crepidostomum nemachilus & 2 & Barbatula toni & This study & FR821408 - FR821409 \\
Crepidostomum cornutum & 1 & Lepomis gulosus & Curran et al., 2006 & EF032695 \\
Megalogonia ictaluri & 1 & Ictalurus punctatus & Curran et al., 2006 & EF032694 \\
Bunodera acerinae & 1 & Gymnocephalus cernuus & Petkeviciute et al., 2010 & GU462122 \\
Bunodera luciopercae & 1 & Perca fluviatilis & Petkeviciute et al., 2010 & GU462124 \\
Allocreadium lobatum & 1 & Semotilus corporalis & Curran et al., 2006 & EF032693 \\
Allocreadium isoporum & 1 & Alburnus alburnus & Petkeviciute et al., 2010 & GU462126 \\
Callohelmis pichelinae & 1 & Femigymnus melapterus & Bray et al., 2009 & FJ788495 \\
\hline
\end{tabular}


DNA extraction was performed from whole worms with silica technique as follows: 1) Trematode specimens were dried and homogenized in 3 M Guanidine thyocyanate. 2) Homogenate was incubated for 10 minutes at $57^{\circ} \mathrm{C}$. 3) Water suspension of silica (silicium dioxide) was added to homogenate ( $5 \mu \mathrm{l}$ of $50 \%$ suspension per 2 $\mu \mathrm{g}$ of expected amount of DNA), mixed and incubated about 5 minutes at $57^{\circ} \mathrm{C}$. 4) Silica/Guanidine solution was centrifuged for $15 \mathrm{sec}$. at 10,000 rpm, supernatant was elucidated. 5) Sediment was washed using cold washing buffer (20 mM TRIS-HCl, $\mathrm{pH}=7.4,1 \mathrm{mM}$ EDTA, $50 \mathrm{mM} \mathrm{NaCl}, 50 \%$ ethanol) for four times by adding of $500 \mu \mathrm{l}$ of the washing buffer, mixing and centrifuging as in previous step. 6) Sediment was dried in air for about one hour and then was resuspended in 100 $150 \mu$ of nuclease free water, mixed and incubated for 10 minutes at $57^{\circ} \mathrm{C}$. 7) Water suspension was centrifuged for 2 minutes at 12,000 rpm, supernatant was transferred to the clean tubes and used for PCR.

The 28S rRNA gene was amplified using the polymerase chain reaction (PCR) with the following primers: DIGl2 (5'-AAG CAT ATC ACT AAG CGG-3') and 1500R (5'-GCT ATC CTG AGG GAA ACT TCG-3') [21]. Initial PCR reaction was carried out in a total volume of $20 \mu \mathrm{l}$. Each reaction contained $0.25 \mathrm{mM}$ of each primer pair, combined with $1 \mu \mathrm{l}$ of aqueous solution of DNA, 10x Taq buffer, 1.25 mM dNTP, 1.5 mM magnesium, and 1 unit of Taq polymerase. Amplification of a 1200-bp fragment of 28S rDNA was performed in a GeneAmp 9700 (Applied Biosystems) with 3 min denaturation hold at $94^{\circ} \mathrm{C} ; 40$ cycles of $30 \mathrm{~s}$ at $94^{\circ} \mathrm{C}, 30 \mathrm{~s}$ at $52^{\circ} \mathrm{C}$, 2 min at $72^{\circ} \mathrm{C}$ and $7 \mathrm{~min}$ extension hold at $72^{\circ} \mathrm{C}$. PCR contamination control was performed by including negative controls alongside positive controls, using both primers. PCR products were initially directly sequenced using ABI Big Dye Terminator v.3.1 Cycle Sequencing kit (as instructed by manufacturer) and internal sequencing primers: 300F, ECD2, 900F, 1200R [21]. Reading of the cycle PCR products was performed with ABI 3130 genetic analyzer of Institute of Biology and Soil Sciences FEB RAS. Sequences of Crepidostomum spp. in this study were aligned with $28 \mathrm{~S}$ sequence data of other species downloaded from NCBI GenBank database, representing following genera of the family Allocreadiidae: Crepidostomum, Megalogonia, Allocreadium, Bunodera. Also we used Callohelmis pichelinae as an outgroup [22] (Table 1).

DNA sequences were assembled with SeqScape v.2.6 software and aligned using MEGA 5.0 [23] alignment explorer with default options. Regions that could not be aligned unambiguously were excluded from the analyses. The number of variable, parsimony-informative sites, nucleotide composition and substitutions were obtained in MEGA 5.0. Frequencies of different substitution types and substitution rate were calculated using test of sub stitution pattern 4 by 4 . Genetic divergence was estimated using genetic p-distance values, which were calculated by including all substitution types. Phylogenetic analysis of nucleotide sequences was undertaken, using all accessible methods, including maximum parsimony, maximum likelihood and Bayesian methods. All distance and parsimony trees were reconstructed with MEGA 5.0 and Bayesian inference was obtained using MrBayes v. 3.1.2 software [24]. The resulting networks were rooted with the outgroup taxa. Phylogenetic algorithms ML and BI performed using the GTR + G model (general-time reversible model with gamma distribution). This model showed the best fit to the data using Modeltest v. 3.07 software [25] using Akaike's information criterion [26]. Bayesian inference was employed using the following nucleotide substitution parameters: lset nucmodel $=4$ by 4 , nst $=6$, rates $=$ gamma. Mcmc algorithm was performed using 4,000,000 generations and 2 independent runs. Burn-in (sump and sumt) values were 80000. A nonparametric bootstrap with 1000 replicates was used to evaluate the robustness of the clusters through nodal support [27] for maximum parsimony and maximum likelihood algorithms. Nodal support for Bayesian algorithm was estimated by posterior probabilities [28]. Kishino-Hasegawa [29] and Shimodaira-Hasegawa [30] tests for phylogenetic trees were performed using PAUP 4b10 [31].

\section{RESULTS}

In the present study data on the genetic divergence and systematic of the far eastern species of the genus Creidostomum were obtained, using 28S rDNA partial sequences. Amplicons were about 1200 bp in length and the sequences, using for analysis after alignment were 1151 bp, including 70 variable and 66 parsimony-informative sites. There were no significant differences in nucleotide composition of 28S rDNA of the Crepidostomum species in comparison with the specimens from another genera and families of trematodes: $\mathrm{A}=20.7 \%$, $\mathrm{T}$ $=25.6 \%, \mathrm{C}=21.7 \%, \mathrm{G}=32 \%$.

The substitution pattern analysis revealed that significant differences of transition/transwersion rate ratio bias values (R) obtained by pairwise comparision of $28 \mathrm{~S}$ rDNA sequences of different Crepidostomum species (Table 2). Minimal R values were obtained by comparision of C. cf. auriculatum and other Crepidostomum species $(\mathrm{R}=2.26-2.74)$. Values of this parameter were 22.38 and 31.33 between C. cf. farionis/C. cf. metoecus and C. $c f$. farionis/C. nemachilus, respectively, indicating bias towards transitions between sequences.

Genetic divergence between far eastern Crepidostomum species ranged from 0 (C. $c f$. metoecus/C. nema- 
chilus) to $3.8 \%$ (C. cf. auriculatum/C. cf. farionis) with a mean value $3.2 \%$ (Table 3). Divergence between $28 \mathrm{~S}$ rDNA sequences between C. $c$ f. farionis and C. nemachilus was $3.1 \%$ that close to the mean interspecific divergence between Creidostomum species. However, there are no divergence between 28S rDNA sequences of C. nemachilus and C. cf. metoecus in spite of considerable morphological differences. Genetic divergence between C. cf. auriculatum and B. luciopercae was 3.1\% that corresponds with interspecific divergence level of Crepidostomum species. Maximal values of genetic divergence between far eastern Crepidostomum species covered with minimal values of intergeneric divergence (Table 3).

Phylogenetic analysis revealed six clusters with a high statistical support (Figure 1). First one was a basal and formed by the genus Allocreadium, and the second one included C. cf. auriculatum, a parasite of the sturgeons. Third cluster included the genus Bunodera, which was represented by two species: B. luciopercae (Muller, 1776) and B. acerinae Roitman and Sokolov, 1999, which were recognized early [32-34]. The fourth cluster included $C$. cornutum and $M$. ictaluri. Last two clusters corresponded with different Crepidostomum species: C. nemachilus and C. cf. metoecus gathered in a single cluster and C. cf. farionis formed a distinct cluster with a high statistical

Table 2. Transition/transversion ratio bias $\left(R^{*}\right)$, obtained by pairwise comparision of 28S rDNA sequences of different Crepidostomum species.

\begin{tabular}{lccccc}
\hline & & 1 & 2 & 3 & 4 \\
\hline 1 & C.cf. auriculatum & & & & \\
2 & C. cf. farionis & 2.31 & & & \\
3 & C. cf. metoecus & 2.26 & 22.38 & & \\
4 & C. nemachilus & 2.74 & 31.33 & 228.51 & \\
\hline
\end{tabular}

" $R=\left[A \cdot G \cdot k_{1}+T \cdot C \cdot k_{2}\right] /[(A+G) \cdot(T+C)]$, where $k_{1}$ и $k_{2}$ - frequences of transitions between purines and pyrimidines, respectively. $R$ becomes 0.5 when there is no bias towards either transitional or transversional substitution because, when the two kinds of substitution are equally probable, there are twice as many possible transversions as transitions.

Table 3. Genetic divergence (\%) between different species of the family Allocreadiidae using 28S rDNA partial sequences.

\begin{tabular}{lccccccc}
\hline & 1 & 2 & 3 & 4 & 5 & 6 & 7 \\
\hline 1. C. cf. auriculatum & & & & & & & \\
2. C. cf. farionis & 3.8 & & & & & & \\
3. C. cf. metoecus & 3.3 & 3.2 & & & & & \\
4. C. nemachilus & 3.2 & 3.1 & 0 & & & & \\
5. C. cornutum & 4.3 & 4.8 & 2.9 & 2.9 & & & \\
6. B. lucioperca & 3.1 & 5.2 & 4.0 & 4.0 & 4.3 & & \\
7. A. isoporum & 4.1 & 5.8 & 5.1 & 5.1 & 5.5 & 5.6 & \\
\hline
\end{tabular}

support, which was closely related to the (C. nemachilus + C. cf. metoecus) cluster. Genetic divergence between obtained clusters ranged from 3.3\% (clusters IV/V and $\mathrm{V} / \mathrm{VI}$ ) to 6.0 (clusters II/VI). To test of significance of the tree topology, which showed paraphyly of the genus Crepidostomum, we compared this topology with tree constraining this genus as monophyletic using KishinoHasegawa and Shimodaira-Hasegawa tests (Table 4). Obtained results showed significant differences between unconstrained phylogenetic tree, showed a paraphyly of Crepidostomum and phylogenetic tree with constraint monophyly of Crepidostomum for three phylogenetic algorithms used.

\section{DISCUSSION}

This is the first time that 28S sequence data have been used to elucidate the systematics of the far eastern Crepidostomum spp. and our data were useful for delineating some species boundaries and questioning at least one nominal taxon (C. nemachilus). All of the phylogenetic trees demonstrated the same topology and showed a paraphyly of the genus Crepidostomum (Figure 1). Firstly, C. cf. auriculatum, a parasite of the sturgeons, appears as more divergent species, that was reproduced on phylogenetic trees as a distinct cluster, which was not related to other Crepidostomum species. This cluster has a high bootstrap support as so as high mean value of genetic divergence (3.8\%) in comparison with other Crepidostomum species from the Russian Far East (3.08\%). Moreover, C. cf. auriculatum is characterized by lower value of transition/transversion ratio bias $(\mathrm{R}=2.26$ 2.74) in comparison with the other Crepidostomum species (Table 2), indicating slight bias from equal contents of transitions and transversions, i.e. prevalence of transversion substitutions type, which is typical for high level taxa. Results of KH and SH tests confirm significance of high differentiation of C. cf. auriculatum with other Crepidostomum species. In our opinion, presented results showed a currency of the question about systematic position of C. cf. auriculatum that was thought to be considered by Skwortzoff (1927) within the genus Acrolichanus [14].

Analysis of 28S rDNA from 29 specimens of C. $c$. auriculatum, collected from three different fishes (two specimens of Acipenser schrenckii and one of Huso dauricus) showed an absence of variation between obtained sequences. It can be interpreted by limited genetic affinity between C. cf. auriculatum and the host species and suggests that sturgeons were used as definitive host for $C$. cf. auriculatum not so far. Such genetic stability irrespective of the host species was shown for other trematode species which infect different species of animals [35-37]. Moreover, C. cf. auriculatum differentiated from Bunodera luciopercae at interspecific divergence level (3.1\%). Species B. luciopercae is a basal species on 


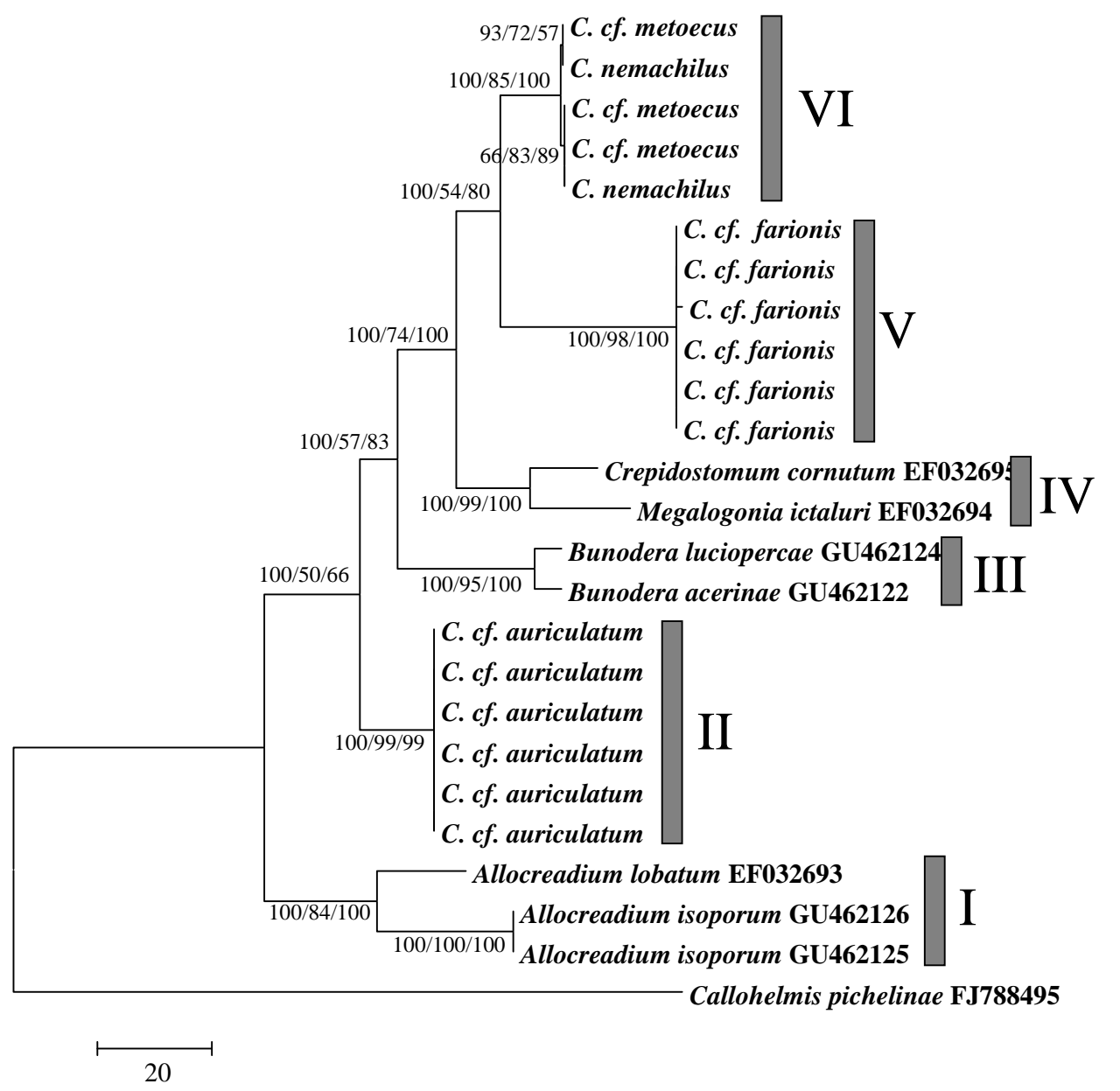

Figure 1. Phylogenetic tree of the family Allocreadiidae, obtained using maximum parsimony algorithm. Nodal numerals are the bootstrap statistics values (\%) for MP/ML/BI algorithms, respectively. Roman numerals correspond to number of cluster, discussed in the text.

Table 4. Comparison by $\mathrm{KH}$ and $\mathrm{SH}$ test of log-likelihood scores among unconstrained and constrained monophyletic trees of the genus Crepidostomum. ${ }^{*} \mathrm{P}<0.05$. Both tests showed significant differences between unconstrained tree, showed a paraphyly of $C r e-$ pidostomum and phylogenetic tree with constraint monophyly of Crepidostomum for three phylogenetic algorithms used.

\begin{tabular}{|c|c|c|c|c|c|}
\hline Algorithm & Tree & $-\ln \mathrm{L}$ & Diff -ln L & P (KH-test) & $\mathrm{P}$ (SH-test) \\
\hline \multirow{2}{*}{ Maximum likelihood } & Unconstrained & 4162.43 & (best) & \multirow{2}{*}{$0.000^{*}$} & \multirow{2}{*}{$0.033^{*}$} \\
\hline & Constraint monophyly & 4203.16 & 40.73 & & \\
\hline \multirow{2}{*}{ Maximum parsimony } & Unconstrained & 4140.55 & (best) & \multirow{2}{*}{$0.000^{*}$} & \multirow{2}{*}{$0.002^{*}$} \\
\hline & Constraint monophyly & 4205.68 & 65.13 & & \\
\hline Bayesian inference & Unconstrained & 4150.63 & (best) & $0.000^{*}$ & $0.002^{*}$ \\
\hline
\end{tabular}

the phylogenetic relationships of the genus Bunodera, which considered as the first parasite of the percid fishes ancestor [38]. Such close relationships possibly suggested that percid fishes could be common to Bunodera species and $C$. $c f$. auriculatum in the past. Sturgeons, therefore, possibly become definitive host for C. $c f$. auriculatum during recent host-switching processes.

Secondly, our results showed close relationships of Megalogonia ictaluri and Crepidostomum cornutum, ob- tained from USA (GenBank data). This result confirms the point of Caira (1989) [3] about the membership of Megalogonia species to the genus Crepidostomum in spite of the point of Curran et al. (2006), which accept the genus Megalogonia [39].

Species C. cf. farionis and C. $c f$. metoecus have considerable external morphological differences between themselves, as so distribution and size of dorsal and dorsolateral oral lobes and tegumental papillae on anterior 
end of body $[3,4,40]$. Also these two species differ by form of the genital bursa [1]. C. nemachilus, included in our investigations, has the same form of the oral lobes and tegumental papillae as so as C. $c$ f. farionis, and the form of genital bursa resembles with C. cf. metoecus. However, C. nemachilus is characterized by irregularity of testicles surface unlike both C. $c f$. farionis and C. cf. metoecus. C. nemachilus, therefore, can be recognized as a possible distinct species by general morphology, which will be presented in a separate article. In the present study, genetic divergence between C. cf. farionis and $C$. cf. metoecus was $3.1 \%$ as so as between C. cf. farionis and $C$. nemachilus that corresponds to mean value of interspecific values range of Crepidostomum species (3.2\%).

Species C. cf. farionis and C. nemachilus, therefore, cannot be recognized as synonymous taxa using both morphological and genetic criteria. However, this conclusion needs to be examined using C. cf. farionis from type location, because of ambiguous taxonomy of C. $c f$. farionis from Russian Far East, which was firstly described as C. ussuriensis Layman, 1930 and reduced to synonym with C. cf. farionis without sufficient evidence. On the other hand, our results show high genetic identity of 28S rDNA sequences of C. nemachilus and C. cf. metoecus (one substitution per $1151 \mathrm{bp}$ ) in spite of their considerable morphological distinctions. This taxonomical problem need to be resolved by complex approach, including detailed description of life cycle and using more variable molecular markers for estimation of genetic divergence between these two species.

\section{ACKNOWLEDGEMENTS}

This study was supported by grant № 13-III-B-06-056. We would like to thank the management of Pacific Scientific Research Fisheries Center (Khabarovsk city). Also we'd like to thank Ph.D. Tomas Scholz (Institute of Parasitology, BC, ASCR) for the detailed edition of the text of the article. A special thanks to Ph.D. Alexey Katokhin (Institute of Cytology and Genetics SD RAS) for providing a DNA extraction technique details.

\section{REFERENCES}

[1] Skrjabin, K.I. and Koval, V.P. (1966) The superfamily Allocreadioidea Nicoll. 1934. In: Skrjabin, K.I. and Koval, V.P., Eds., Trematodes of Animals and Man and the Diseases Caused by Them, Publ. House Nauka, Moscow, 175-517.

[2] Bykhovskaya-Pavlovskaya, X.E. and Kulakova, A.P. (1987) Identification guide of parasites of freshwater fishes of USSR fauna. Trematoda. Publ. House Nauka, Leningrad.

[3] Caira, N.J. (1989) A revision of the North American papillose Allocreadiidae (Digenea) with independent cladis- tic analyses of larval and adult forms. Bulletin of The University of Nebraska State Museum, 11, 1-55.

[4] Caira, J.N. and Bogea, T. (2005) Keys to the Trematoda. family Allocreadiidae. CABI Publishing and the Natural History Museum, Walingford.

[5] Zd'arska, Z. and Nebesarova, J. (2002) Ultrastructure of pigmented photoreceptor of adult Crepidostomum metoecus (Trematoda: Bunoderidae). Folia Parasitologica, 49, 165-166. http://dx.doi.org/10.14411/fp.2002.030

[6] Platta, C. and Choudhury, A. (2006) Systematic position and relationships of Paracreptotrematina limi, based on partial sequences of 28S rRNA and cytochrome c oxidase subunit 1 genes. Journal of Parasitology, 92, 411-413. http://dx.doi.org/10.1645/GE-3521RN.1

[7] Perez-Ponce de Leon, G., Choudhury, A., Rozas-Valdes, R. and Mejia-Madrid, H. (2007) The systematic position of Wallinia spp. and Margotrema spp. (Digenea), parasites of Middle-American and Neotropical freshwater fishes, based on the 28S ribosomal RNA gene. Systematic Parasitology, 68, 49-55. http://dx.doi.org/10.1007/s11230-006-9081-3

[8] Choudhury, A., Valdes, R.R., Johnson, R.C., Hoffman, B. and Perez-Ponce de Leon, G. (2007) The phylogenetic position of Allocreadiidae (Trematoda: Digenea) from partial sequences of the $18 \mathrm{~S}$ and $28 \mathrm{~S}$ ribosomal RNA genes. Journal of Parasitology, 93, 192-196. http://dx.doi.org/10.1645/GE-966R.1

[9] Layman, E.M. (1930) Parasitic worms from fishes of Peter the Great Bay. Bulletin of Pacific Fishery Research Station, 3, 1-120.

[10] Krotov, A.I. (1959) Two new parasitic worms from vertebrates of Sakhalin Island. Acta Veterenaria Hungarica, 9, 7-12.

[11] Shimazu, T. (1990) Trematodes of the genus Crepidostomum (Digenea: Allocreadiidae: Crepidostominae) from freshwater fishes of Japan. Journal of Nagano Prefectural College, 45, 1-14.

[12] Choudhury, A. (1997) Parasites of lake sturgeon, Acipenser fulvescens: Systematics and biogeography. PhD Dissertation, University of Manitoba Press, Manitoba.

[13] Linton, E. (1987) Notes on the trematode parasites of fishes. Proceedings of the United States National $\mathrm{Mu}$ seum, 2, 507-548.

[14] Skwortzoff, A.A. (1927) To the anatomy of the trematode Acrolichanus auriculatus (Wedl, 1856) in the sterlet of Volga River basin. Proceedings by Helminthology dedicated to Professor K.I. Skrjabin, 1, 276-286.

[15] Skwotzoff, A.A. (1928) Uber die Helminthenfauna des Wolgasterlets. Zoologische Jahrbucher, 54, 557-577.

[16] Hopkins, S.H. (1933) The morphology, life histories and relationships of the papillose Allocreadiidae (Trematoda). Preliminary Report. Zoologische Anzeiger, 103, 65-74.

[17] Kaw, B.L. (1944) Studies of the helminth parasites of Kashmir. Part III. Description of a new allocreaid, Crepidostomum indicum from a freshwater fish, Schizothorax niger, from the Dal Lake, Kashmir. Proceedings of the 
Indian Academy of Science, Series Biology, 20, 72-77.

[18] Skrjabina, E.S. (1974) Helminthes of acipenserid fishes (Acipenserdae Bonaparte, 1831). Publ. House Nauka, Moscow, 1974.

[19] Shul'man, S.S. (1954) A review of parasite fauna of fishes of the USSR. Proceedings of Leningrad Society of Naturalists, 72, 190-254.

[20] Hopkins, S.H. (1934) The papillose Allocreadiidae. A study of their morphology, life histories and relationships. Illinois Biological Monographs, 13, 6-77.

[21] Tkach, V.V., Littlewood, D.T.J., Olson, P.D., Kinsella, J.M. and Swiderski, Z. (2003) Molecular phylogenetic analysis of the Microphalloidea Ward, 1901 (Trematoda: Digenea). Systematic Parasitology, 56, 1-15. http://dx.doi.org/10.1023/A:1025546001611

[22] Bray, R.A., Waeschenbach, A., Cribb, T.H., Weedall, G.D., Dyal, P. and Littlewood, D.T.J. (2009) The phylogeny of the Lepocreadiidae (Platyhelminthes: Digenea) inferred from nuclear and mitochondrial genes: Implications for their systematics and evolution. Acta Parasitologica, 54, 310-329.

http://dx.doi.org/10.2478/s11686-009-0045-z

[23] Tamura, K, Peterson, D, Peterson, N., Stecher, G, Nei, M. and Kumar S. (2011) MEGA5: Molecular Evolutionary Genetics Analysis using Maximum likelihood, evolutionary distance, and maximum parsimony methods. Molecular Biology and Evolution, 28, 2731-2739. http://dx.doi.org/10.1093/molbev/msr121

[24] Huelsenbeck, J.P. (2000) Mr Bayes: Bayesian inference of phylogeny. Department of Biology, University of Rochester, Rochester.

[25] Posada, D. and Crandall, K.A. (1998) Modeltest: Testing the model of DNA substitution. Bioinformatics, 14, 817818. http://dx.doi.org/10.1093/bioinformatics/14.9.817

[26] Akaike, H. (1974) A new look at the statistical model identification. IEEE Transactions of Automatic Control, 19, 716-723. http://dx.doi.org/10.1109/TAC.1974.1100705

[27] Felsenstein, J. (1985) Confidence limits on phylogenies: An approach using bootstrap. Evolution, 39, 783-791. http://dx.doi.org/10.2307/2408678

[28] Huelsenbeck, J.P., Ronquist, F., Nielsen, R. and Bollback, J.P. (2001) Bayesian inference of phylogeny and its impact on evolutionary biology. Science, 294, 2310-2314. http://dx.doi.org/10.1126/science.1065889

[29] Kishino, H. and Hasegawa, M. (1989) Evaluation of the maximum likelihood estimate of the evolutionary tree topologies from DNA sequence data, and the branching order in Hominoidea. Journal of Molecular Evolution, 29, 170-179. http://dx.doi.org/10.1126/science.1065889

[30] Shimodaira, H. and Hasegawa, M. (1999) Multiple comparisons of log-likelihoods with applications to phylogenetic inference. Molecular Biology and Evolution, 16, 1114-1116. http://dx.doi.org/10.1093/oxfordjournals.molbev.a026201

[31] Shimodaira H. and Hasegawa M. (1999) Multiple comparisons of log-likelihoods with applications to phylogenetic inference. Molecular Biology and Evolution, 16, 1114-1116.

[32] Swofford, D.L. (2003) PAUP*. Phylogenetic analysis using parsimony (* and other methods). Version 4. Sinauer Associates, Sunderland.

[33] Roitman, V.A. and Sokolov, S.G. (1999) Taxonomic analysis of Bunodera luciopercae (Muller, O.F., 1776) in Palearctic region of its area. Interrelationships of parasite and host, Institute of Parasitology, Moscow, 73-87.

[34] Sokolov, S.G., Tseitlin, D.G., Afanasyev, K.I., Malinina, T.V. and Rubtsova, G.A. (2006) A comparative study of two sympatric subspecies of trematodes, Bunodera luciopercae luciopercae (Muller, 1776) and B. l. acerinae Roitman et Sokolov, 1999 (Trematoda: Bunoderidae). Invertebrate Zoology, 3, 209-223.

[35] Petkeviciute, R., Stunzenas, V., Staneviciute, G. and Sokolov, S.G. (2010) Comparison of the developmental stages of some European allocreadiid trematode species and a clarification of their life cycles based on ITS 2 and 28S sequences. Systematic Parasitology, 76, 169-178. http://dx.doi.org/10.1007/s11230-010-9249-8

[36] Nolan, M.J. and Cribb, T.H. (2005) The use and implication of ribosomal DNA sequencing for the discrimination of digenean species. Advances in Parasitology, 60, 101163. http://dx.doi.org/10.1016/S0065-308X(05)60002-4

[37] Otranto, D., Rehbein, S., Weigl, S., Cantacelli, C., Parisi, A., Lia, R.P. and Olson, P.D. (2007) Morphological and molecular differentiation between Dicrocoelum dendriticum (Rudolphi, 1819) and Dicrocoelum chinensis (Sudarikov and Ryjikov, 1951) Tang and Tang, 1978 (Platyhelmin- thes: Digenea). Acta Tropica, 104, 91-98. http://dx.doi.org/10.1016/j.actatropica.2007.07.008

[38] Maurelli, M.P., Rinaldi, L., Capuano, F., Perugini, A.G., Veneziano, V. and Cringoli, G. (2007) Characterization of the $28 \mathrm{~S}$ and the second transcribed spacer of ribosomal DNA of Dicrocoelum dendriticum and Dicrocoelum hospes. Parasitology Research, 101, 1251-1255. http://dx.doi.org/10.1007/s00436-007-0629-1

[39] Choudhury, A. and Regagnon, V.L. (2005) Molecular phylogenetics and biogeography of Bunodera spp. (Trematoda: Allocreadiidae), parasites of percid and gasterosteid fishes. Canadian Journal of Zoology, 83, 1540-1546.

[40] Curran, S.S., Tkach, V.V. and Overstreet, R.M. (2006) A review of Polylekithum Arnold, 1934 and its familial affinities using morphological and molecular data, with description of Polylekithum catahoulensis sp. nov. Acta Parasitologica, 51, 238-248. http://dx.doi.org/10.2478/s11686-006-0037-1

[41] Moravec, F. (2002) External morphological differences between Crepidostomum farionis and Crepidostomum metoecus (Trematoda: Allocreadiidae), parasites of salmonids, as revealed by SEM. Folia Parasitologica, 49, 211-217. 